ARTICLE

Received 24 Feb 2014 | Accepted 14 Apr 2014 | Published 27 May 2014 DOl: 10.1038/ncomms4882

\title{
A design strategy for the hierarchical fabrication of colloidal hybrid mesostructures
}

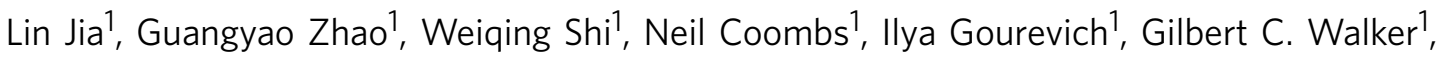 \\ Gerald Guerin ${ }^{1}$, Ian Manners ${ }^{2} \&$ Mitchell A. Winnik $^{1}$
}

\begin{abstract}
Advances in nanotechnology depend upon expanding the ability to create new and complex materials with well-defined multidimensional mesoscale structures. The creation of hybrid hierarchical structures by combining colloidal organic and inorganic building blocks remains a challenge due to the difficulty in preparing organic structural units of precise size and shape. Here we describe a design strategy to generate controlled hierarchical organic-inorganic hybrid architectures by multistep bottom-up self-assembly. Starting with a suspension of large inorganic nanoparticles, we anchor uniform block copolymer crystallites onto the nanoparticle surface. These colloidally stable multi-component particles can initiate the living growth of uniform cylindrical micelles from their surface, leading to three-dimensional architectures. Structures of greater complexity can be obtained by extending the micelles via addition of a second core-crystalline block copolymer. This controlled growth of polymer micelles from the surface of inorganic particles opens the door to the construction of previously inaccessible colloidal organic-inorganic hybrid structures.
\end{abstract}

\footnotetext{
${ }^{1}$ Department of Chemistry, University of Toronto, 80 St. George Street, Toronto, Ontario, Canada M5S 1H6. ${ }^{2}$ School of Chemistry, University of Bristol, Bristol BS8 1TS, UK. Correspondence and requests for materials should be addressed to G.G. (email: gguerin@chem.utoronto.ca) or to I.M. (email: ian.manners@bristol.ac.uk) or to M.A.W. (email: mwinnik@chem.utoronto.ca).
} 
$\mathrm{N}$ ature uses a hierarchy of self-assembly steps to construct functional hybrid structures from inorganic and organic building blocks. Laboratory-based synthetic approaches are now beginning to reach similar levels of exquisite control in the creation of nanoscale and mesoscale architectures ${ }^{1-5}$, using well-defined nanomaterials as building blocks. For example, a variety of supramolecular structures have been formed through the secondary association of various organic building blocks ${ }^{6}$ including block copolymer (BCP) micelles ${ }^{7-12}$. Higher order structures have also been formed by the self-assembly of inorganic nanoparticles (NPs), including particles with different but complementary shapes, and rod-like particles coated at the ends with DNA or synthetic polymers ${ }^{13-17}$. Other types of structures have been generated using BCP micelles, viruses or other scaffolds as templates for decoration with small inorganic $\mathrm{NPs}^{13,18}$. Although these inorganic NPs add a level of hierarchy to the structure and can have an important functional role (optical, catalytic), they are too small to serve as building blocks for the construction of higher order structures.

In contrast, there are only rare examples of colloidal mesoscale structures that combine self-assembled organic building blocks and large inorganic NPs, particularly with the inorganic NP as the central structural unit ${ }^{19,20}$. One example that we are aware of consists of DNA origami assemblies attached to a central gold $\mathrm{NP}$, forming 'core-satellite' architectures with smaller gold NPs at the periphery. Beautiful as these structures are, the size is limited by the dimensions of the DNA origami and the solvent is restricted to water. It would be a major step forward to enlarge the spectrum of accessible structures, over a larger range of sizes, using a broader variety of organic building blocks, particularly $\mathrm{BCP}$ micelles. There are multiple advantages of using $\mathrm{BCP}$ micelles as building blocks. Many different BCPs are available, with different chemistries and different functionalities for the core-forming and corona-forming blocks. They can self-assemble in a variety of different selective solvents to form specific morphologies. One can chemically post-modify the corona block of a micelle without altering the properties of its core. Finally, this library of BCPs would offer different ways to anchor the micelles to the surfaces of inorganic particles. This would enable the construction of previously inaccessible colloidal organicinorganic hybrid mesostructures.

We address this challenge via a multistep, bottom-up selfassembly approach to grow uniform cylindrical BCP micelles from the surface of a large inorganic NP as the structural foundation stone. To ensure a high level of structural control over each step of sample preparation, we focus on the fabrication of hybrid hierarchical structures that are colloidally stable during the entire self-assembly procedure. Our examples employ uniform spherical or rod-like inorganic NPs, but our methodology can be applied to central structural units of any size and shape. Then, in a selective solvent, we attach short fragments of a carefully designed core-crystalline BCP micelle. The core polymer is chosen for its ability to initiate crystallization-driven selfassembly (CDSA) of cylindrical BCP micelles when unimer is added to the solution, and the corona must provide strong adhesion to the surface of the inorganic particle. Many BCPs consisting of a long soluble block attached to a shorter crystallizable block $^{21}$ are potential candidates for this approach. While CDSA has been reported for BCPs with poly (3-hexylthiophene) ${ }^{22}$, polylactide ${ }^{23}$, polycaprolactone ${ }^{24}$ and polyethylene $^{25}$ as the crystallizable block, one has the greatest control over this kind of seeded growth for polyferrocenylsilane (PFS) BCPs. Under appropriately chosen self-assembly conditions, all of the added unimer of a PFS BCP grow off the ends of the crystallite seeds in the sample, and uniform elongated structures can be formed ${ }^{26-31}$. The 'living' nature of micelle elongation by CDSA thus becomes a tool to control the morphological homogeneity of the structure.

\section{Results}

Preparation of sunflower-like assemblies. To develop our strategy, we began with the fact that a silica surface is rich in $\mathrm{Si}$ $\mathrm{OH}$ groups that can form hydrogen bonds in a cooperative way with poly(2-vinylpyridine) (P2VP). Thus, we selected $\mathrm{PFS}_{30}-b$ $\mathrm{P}_{2} \mathrm{VP}_{300}$ (the subscripts refer to the number average degrees of polymerization) as the BCP and $250 \mathrm{~nm}$ diameter silica $\mathrm{NPs}\left(\mathrm{SiO}_{2}\right.$ NPs, Supplementary Fig. 1) as our initial foundation stone. Long cylindrical micelles of $\mathrm{PFS}_{30}-b-\mathrm{P}_{2} \mathrm{VP}_{300}$ in 2-propanol (2-PrOH) (Supplementary Fig. 2a) were prepared as described previously ${ }^{32}$ and subjected to mild sonication to obtain a suspension of seed crystallite micelles (Supplementary Fig. 2b), characterized by a number average length $L_{\mathrm{n}}=60 \mathrm{~nm}\left(\mathrm{PDI}_{\mathrm{TEM}}=L_{\mathrm{w}} / L_{\mathrm{n}}=1.09\right)$ uniform in width (number average width, $W_{\mathrm{n}}=19 \mathrm{~nm}$, $\mathrm{PDI}_{\mathrm{TEM}}=1.03$ ).

An aliquot of these crystallites was added to a suspension of the $\mathrm{SiO}_{2} \mathrm{NPs}$ and allowed to age for $24 \mathrm{~h}$. Transmission electron microscopy (TEM) images of this sample are shown in Fig. 1a and Supplementary Fig. 3. The excess of crystallites present in the a
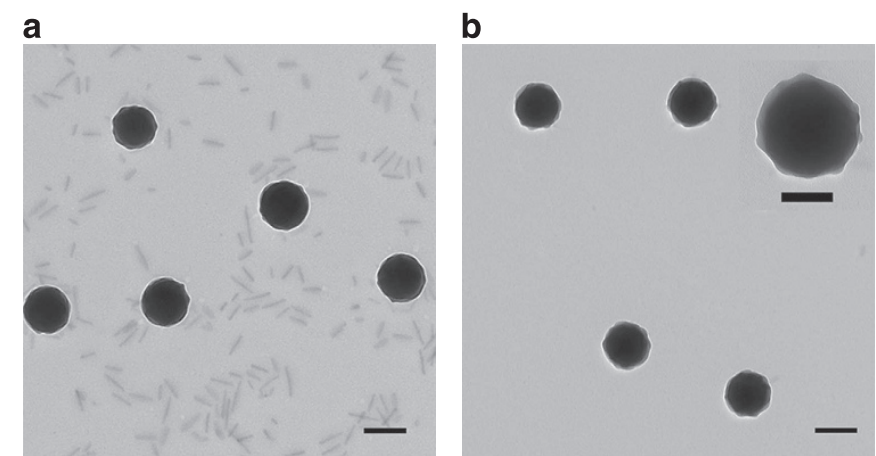

c
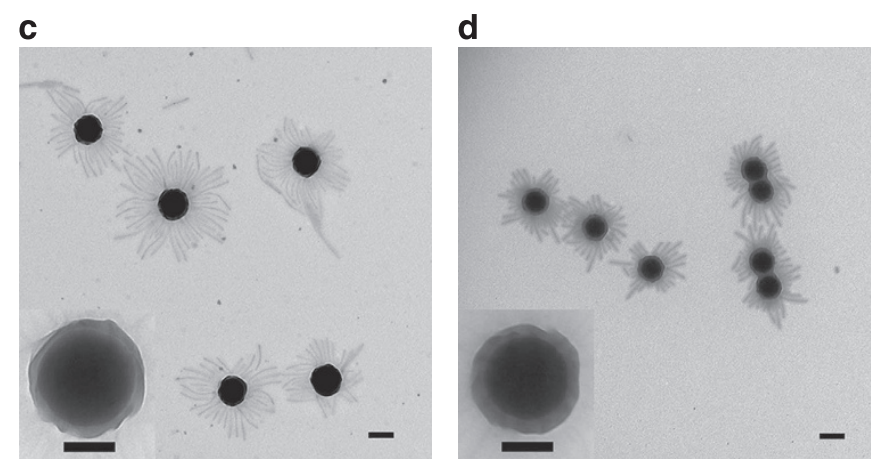

Figure 1 | Preparation of sunflower-like assemblies through seeded growth and self-seeding. (a) TEM image of a mixture of $\mathrm{SiO}_{2} \mathrm{NPs}$ and excess $\mathrm{PFS}_{30}-b-\mathrm{P}_{2} \mathrm{VP}_{300}$ seeds prepared in $2-\mathrm{PrOH}$ and aged for $24 \mathrm{~h}$. (b) TEM image of the seed-coated $\mathrm{SiO}_{2} \mathrm{NPs}$ after removal of excess seeds by sedimentation-resuspension in $2-\mathrm{PrOH}$. The inset shows a single seed-coated $\mathrm{SiO}_{2} \mathrm{NP}$ at higher magnification. (c) TEM image of sunflower hybrid assemblies prepared by addition of $\mathrm{PFS}_{30}-b-\mathrm{P}_{2} \mathrm{VP}_{300}$ in $\mathrm{THF}$ $\left(15 \mu \mathrm{l}, 10 \mathrm{mg} \mathrm{ml}^{-1}\right)$ to 2 -propanol $(1 \mathrm{ml})$ containing seed-coated $\mathrm{SiO}_{2} \mathrm{NPs}$ $\left(0.5 \mathrm{mg} \mathrm{ml}^{-1}\right)$ and aged for $24 \mathrm{~h}$. The inset shows a single sunflower assembly. (d) TEM image of sunflower-like hybrid assemblies prepared by subjecting the mixture of $\mathrm{PFS}_{30}-b-\mathrm{P}_{2} \mathrm{VP}_{300}$ seeds and $\mathrm{SiO}_{2} \mathrm{NPs}$ (as in a) to two heating/cooling cycles ( 30 and $90 \mathrm{~min}$ at $90^{\circ} \mathrm{C}$ ) followed by aging at room temperature for $24 \mathrm{~h}$. The inset is an image of a single hybrid nanostructure at higher magnification. In the text and the Supplementary Materials, the terms $\mathbf{1 b}, \mathbf{1 c}$ and $\mathbf{1 d}$ refer to the samples whose structures are shown in b-d, respectively. Scale bars, $200 \mathrm{~nm}$ and $100 \mathrm{~nm}$ in the insets. 
solution could be removed by sedimentation and redispersion in fresh 2-PrOH solvent (Fig. $1 \mathrm{~b}$ and Supplementary Fig. 4). It is important to note that the seed-coated $\mathrm{SiO}_{2} \mathrm{NPs}$ are colloidally stable. They can be submitted to several cycles of centrifugation/ redispersion and can be stored for many days, without showing irreversible aggregation. This approach is different from the kinetic trapping of transient PFS homopolymer suspensions by PFS BCP reported recently ${ }^{33}$, where one has only a narrow time window for generating multiarmed structures. The TEM image in the inset of Fig. $1 \mathrm{~b}$ shows that the crystallites adsorbed to the surface of the silica, adding a layer $\sim 30 \mathrm{~nm}$ thick. Analysis of the seed-coated $\mathrm{SiO}_{2}$ NPs by energy-dispersive X-ray (EDX, Supplementary Fig. 5) shows strong signals of iron and nitrogen. We refer to these seed-coated NPs both as $\mathbf{1} \mathbf{b}$ and as seeds@SiO ${ }_{2}$ NPs. To use these NPs as substrates for seeded growth, we added an aliquot of $\mathrm{PFS}_{30}-b-\mathrm{P}_{2} \mathrm{VP}_{300}$ in tetrahydrofuran (THF) to a suspension of seed-coated $\mathrm{SiO}_{2} \mathrm{NPs}$ in 2-PrOH. After brief swirling, the mixture was set aside to age for $24 \mathrm{~h}$. In this way, the sunflower-like structures (1c) as seen in Fig. 1c and Supplementary Fig. 6 were obtained. This result demonstrates that the $\mathrm{PFS}_{30}-b-\mathrm{P}_{2} \mathrm{VP}_{300}$ crystallites attached to the NP surface are effective nucleating agents for micelle growth. Because of the large dark circular core seen in the TEM images, we refer to these structures as 'sunflower' assemblies.

A good measure of the control we have over seeded growth is the uniformity of the length of the petal-like micelles that emanate from the central particle. Multiple TEM images were analysed using the software ImageJ, giving a mean petal length $L_{\mathrm{n}}=224 \mathrm{~nm}$ with a narrow distribution $\left(\mathrm{PDI}_{\mathrm{TEM}}=1.03\right)$. Accompanying these sunflower-like structures were occasional isolated linear micelles (Supplementary Fig. 6) with an average length of $547 \mathrm{~nm}\left(\mathrm{PDI}_{\mathrm{TEM}}=1.01\right)$. These micelles were most likely nucleated by a few free seed crystallites present in the micelles@SiO $\mathrm{Si}_{2}$ NP solution and grew from both ends of the $60 \mathrm{~nm}$ long seeds. The mean length of the free micelles is approximately twice that of the petals plus the length of the seed.

A second processing protocol also leads to the formation of sunflower assemblies. When the solution containing the mixture depicted in Fig. 1a was subjected to two heating-cooling cycles $\left(90^{\circ} \mathrm{C}\right.$, then room temperature) and allowed to age for $24 \mathrm{~h}$, the structures 1d shown in Fig. 1d and Supplementary Fig. $7 c$,d were obtained. The fibre-like petals of these sunflowers are all similar in length, with $L_{\mathrm{n}}=204 \mathrm{~nm}\left(\mathrm{PDI}_{\mathrm{TEM}}=1.04\right)$. This protocol is conceptually related to 'self-seeding' in which heating leads to the selective dissolution of the most soluble crystallites ${ }^{34}$. Upon cooling, the solution becomes supersaturated in $\mathrm{BCP}$, which then deposits epitaxially on the remaining seed crystallites in solution. The disappearance of isolated micelles from the solution indicates that all of the micelles formed upon cooling grew from seeds on the surface of the NPs. It also suggests that adsorption of the seed crystallites on the surface of the $\mathrm{SiO}_{2}$ NPs suppressed or retarded their dissolution. The sunflower assemblies obtained in this way (1d) appear to be identical to those obtained by seeded growth (1c), except for differences in the lengths of the petals. The two preparation protocols for the construction of sunflower-like hybrid assemblies are summarized in Fig. 2.

Preparation of butterfly-like assemblies. The seeded growth protocol can in principle be applied to any type of silica-coated colloidal NPs (for example, metal NPs, quantum dots, magnetic NPs) as the substrate for growing fibre-like micelles. To test this idea, we carried out proof of concept experiments on silica-coated nanorods (NRs) of a nickel-hydrazine complex ( $\left.\mathrm{SiO}_{2} @ \mathrm{Ni}-\mathrm{NRs}\right)$ reported recently by Gao et al. ${ }^{35}$ using them as a template for growing fibre-like micelles from the NR surface. To begin, we synthesized a sample of $\mathrm{SiO}_{2} @ \mathrm{Ni}-\mathrm{NRs}$ with a mean length $L_{\mathrm{n}, \text { rod }}=375 \mathrm{~nm}\left(\mathrm{PDI}_{\mathrm{TEM}}=1.10\right)$ and a silica shell $30 \mathrm{~nm}$ thick (Supplementary Fig. 8a). Using the same approach described for seeds@SiO $\mathrm{S}_{2} \mathrm{NPs}$, a suspension of $\mathrm{SiO}_{2} @ \mathrm{Ni}-\mathrm{NRs}$ in 2-PrOH was mixed with $\mathrm{PFS}_{30}-b-\mathrm{P}_{2} \mathrm{VP}_{300}$ seeds and stirred for $24 \mathrm{~h}$. A TEM image of the as-prepared mixture of $\mathrm{SiO}_{2} @ \mathrm{Ni}-\mathrm{NRs}$ and seeds is shown in Supplementary Fig. 8b. Most of the unbound excess $\mathrm{PFS}_{30}-b$ - $2 \mathrm{VPP}_{300}$ seeds were removed by three cycles of sedimentation-resuspension in 2-propanol. The TEM image in Fig. 3a reveals the distinct structure of the $\mathrm{SiO}_{2} @ \mathrm{Ni}-\mathrm{NRs}$ coated with $\mathrm{PFS}_{30}-b-\mathrm{P}_{2} \mathrm{VP}_{300}$ seeds (3a). Most of the BCP seeds lie on the NR surface, presumably to maximize hydrogen bonds between the Si-OH groups of the silica and the P2VP corona of the seed micelles. Fewer seeds are attached to the ends of the NRs.

Seeded growth was carried out by adding an aliquot of $\mathrm{PFS}_{30}-b$ $\mathrm{P}_{2} \mathrm{VP}_{300}$ in THF to the suspension of seed-coated NRs in 2-PrOH. Fibre-like micelles grew from the surface of the NRs as shown in Fig. 3b (TEM images) and in Fig. 3c (atomic force microscopy, AFM, phase images) and Fig. 3d (AFM threedimensional height image). Inspection of these structures (3b) suggests that the fibre-like micelles are primarily oriented perpendicular to the rod axis. This directionality, coupled with the shape of the NR core, is the origin of the butterfly-like shapes of the nanocomposite structures observed on the grid. The micelles were uniform in length $\left(L_{n}=732 \mathrm{~nm}, \mathrm{PDI}_{\mathrm{TEM}}=1.01\right)$. A section analysis (Fig. 3f) of two adjacent structures in the AFM height image in Fig. 3e shows that the NR cores are $\sim 95 \mathrm{~nm}$ high, whereas the individual micelles have a height of $15 \mathrm{~nm}$. The nanocomposite structures were accompanied by small numbers of isolated linear micelles that likely originated from seed micelles not attached to the NRs when the THF solution of BCP was added.

Control of micelle length. From the mechanism of living CDSA, we can anticipate two approaches to control the length of the petal-like micelles in the sunflower hybrid structures. In the first approach, we vary the amount of unimers added to the seeds@$\mathrm{SiO}_{2}$ NPs as shown as pathway $\mathbf{c} \rightarrow \mathbf{d}$ in Fig. 2. If all the seeds initiate micelle growth simultaneously and the micelles grow at the same rate, then the length of the petals should depend upon the ratio of unimers added to seeds present on the surface of the NPs. We demonstrate this idea in Fig. 4a,b (and Supplementary Figs 9 and 10), where we compare TEM images of hybrid structures obtained by adding two different amounts of $\mathrm{PFS}_{30^{-}} b$ $\mathrm{P}^{2} \mathrm{VP}_{300}\left(10 \mathrm{mg} \mathrm{ml}^{-1}\right.$ in THF) to portions of a solution of $\mathbf{1 b}$ (seeds@SiO ${ }_{2} \mathrm{NPs}$ ) in 2-PrOH. Analysis of the micelle lengths in the micrographs indicated that the lengths obtained with the $10 \mu \mathrm{l}$ addition of unimer $\left(4 \mathrm{a}, L_{\mathrm{n}}=366 \mathrm{~nm}, \mathrm{PDI}_{\mathrm{TEM}}=1.04\right)$ was approximately half that of $20 \mu$ addition $\left(\mathbf{4 b}, L_{\mathrm{n}}=704 \mathrm{~nm}\right.$, $\mathrm{PDI}_{\mathrm{TEM}}=1.01$ ).

The second approach involves sequential addition of $\mathrm{BCP}$ to preformed mesostructures. Here we added $2.5 \mu \mathrm{l} \mathrm{PFS}_{30^{-}}-b$ $\mathrm{P}^{2} \mathrm{VP}_{300}$ in THF to an aliquot of solution $4 \mathrm{a}$ and $10 \mu \mathrm{l}$ to an aliquot of solution $4 \mathbf{b}$. After $24 \mathrm{~h}$ aging, we found that the $366 \mathrm{~nm}$ petals of $4 \mathbf{a}$ (Fig. $4 \mathrm{a})$ grew to $510 \mathrm{~nm}\left(\mathbf{4 c}, \mathrm{PDI}_{\mathrm{TEM}}=1.02\right.$, Fig. $4 \mathrm{c}$ and Supplementary Fig. 11), and from $704 \mathrm{~nm}(\mathbf{4 b}$, Fig. 4b) to $1.36 \mu \mathrm{m}\left(4 \mathrm{~d}, \mathrm{PDI}_{\mathrm{TEM}}=1.01\right.$, Fig. $4 \mathrm{~d}$ and Supplementary Fig. 12). These experiments demonstrate that the end of the petals were still active for further growth.

Further functionalization of the hybrid structures. The sequential addition of BCP for petal elongation opens the possibility for constructing many new types of structures through sitespecific placement of different corona chains in the micelles emanating from the NP surface. As a proof of concept, we show, based on an idea in ref. 36 , how one can attach cationic charges to 


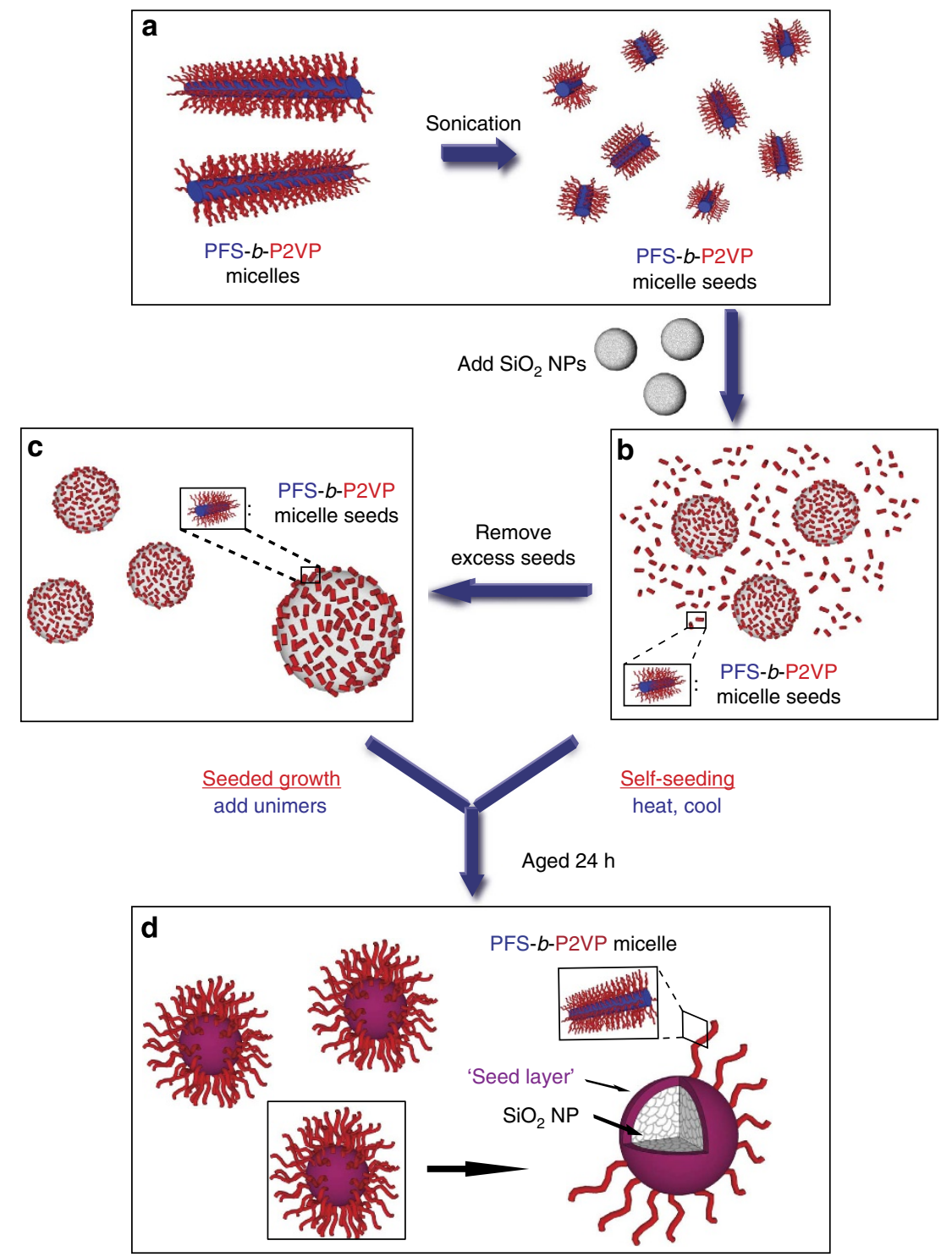

Figure 2 | Protocols to prepare sunflower-like assemblies. (a) Both strategies begin with sonication of elongated PFS- $b$-P2VP micelles. (b) Addition of $\mathrm{SiO}_{2}$ NPs leads to adsorption of PFS- $b$-P2VP seed crystallites, but a large excess of seed crystallites remains in solution. (c) In the 'seeded growth' strategy, the seed-coated $\mathrm{SiO}_{2} \mathrm{NPs}$ are first separated from the excess seeds. Then an aliquot of a concentrated solution of PFS- $b$-P2VP unimers is added, and the mixture is aged to form the mesoscale hybrid structures shown in $\mathbf{d}$. In the 'self-seeding' strategy, the mixture in $\mathbf{b}$ is annealed at $90^{\circ} \mathrm{C}$, leading to the dissolution of the seed crystallites suspended in solution, but preservation of the crystallites bound to the surface of the $\mathrm{SiO}_{2} \mathrm{NPs}$. Upon cooling, micelles grow from the seeds on the NP surface to form hybrid structures indistinguishable from those formed via unimer addition. Both protocols create supersaturated solutions of the BCP in the presence of seed crystallites on the surface of the colloidal nanoparticles, followed by the epitaxial growth of the $B C P$ micelles from the surface-bound seeds.

the tips of the micelles as means of introducing small metal $\mathrm{NPs}^{36}$. To introduce these cationic sites, we took a sample of $\mathrm{PFS}_{30}-b$ - $\mathrm{P}_{2} \mathrm{VP}_{300}$ and partially quaternized the pyridines with methyl iodide $\left(\mathrm{PFS}_{30}-b-\mathrm{P} 2 \mathrm{VP}_{300}\right)$. The challenge that we faced here was to keep the extent of methylation small $(\sim 3 \%)$ to maintain polymer solubility in THF. At this level of methylation, each P2VP chain contains only $\sim 10$ positively charged pyridinium groups. When we added a THF solution of the partially quaternized polymer $\left(\mathrm{PFS}_{30}-b\right.$ - $\mathrm{P} 2 \mathrm{VP}_{300}, 2.5 \mu \mathrm{l}$, $10 \mathrm{mg} \mathrm{ml}^{-1}$ ) to $0.5 \mathrm{ml}$ aliquots of $\mathbf{4 a}$ and $\mathbf{4 b}$ in $2-\mathrm{PrOH}$, we obtained the structures shown, respectively, in Fig. 5a,d. As one might expect, there is insufficient contrast to see the location of the newly added polymer. We note that the average petal lengths of the two sets of structures increased from $L_{\mathrm{n}}=366 \mathrm{~nm}$ in 4 a to
$502 \mathrm{~nm}$ in 5a $\left(\mathrm{PDI}_{\mathrm{TEM}}=1.02\right.$, Fig. 5a), and from $L_{\mathrm{n}}=704 \mathrm{~nm}$ in $4 \mathbf{b}$ to $853 \mathrm{~nm}$ in $5 \mathbf{d}\left(\mathrm{PDI}_{\mathrm{TEM}}=1.01\right.$, Fig. $\left.5 \mathrm{~d}\right)$, introducing sites of positive charge in the distal part of each petal.

To map the location of the cationic charges in the elongated micelles, we treated the suspensions of mesostructures $5 \mathbf{a}$ and $\mathbf{5 d}$ in $2-\mathrm{PrOH} / \mathrm{H}_{2} \mathrm{O}(1: 1(\mathrm{v} / \mathrm{v}))$ with negatively charged $2-\mathrm{nm}$ gold NPs (Au NPs bearing mercaptoacetate surface groups) and obtained colloidally stable solutions of the structures $5 \mathbf{b}$ (Fig. 5b) and 5e (Fig. 5e), respectively. There is a clear indication, especially in high magnification images (TEM Fig. 5c, and dark-field TEM Fig. 5f), of the preferential attachment of the $\mathrm{Au}$ NPs to the ends of the petals where the partially quaternized polymer was located. More important, these experiments demonstrate that the hybrid mesostructures maintain their 
a

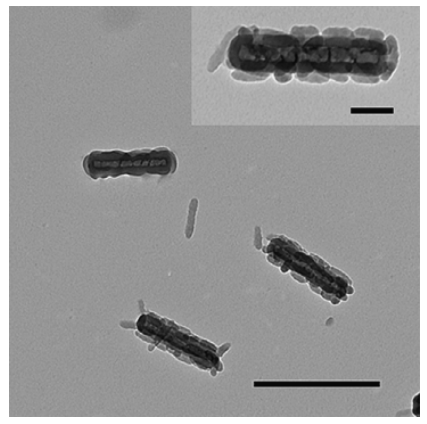

d

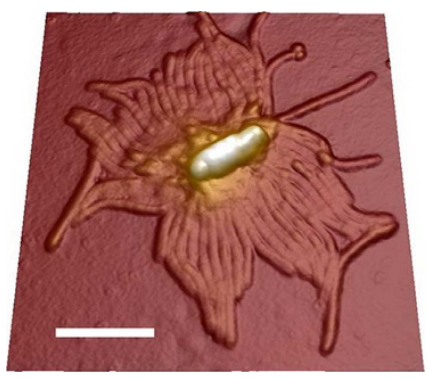

b

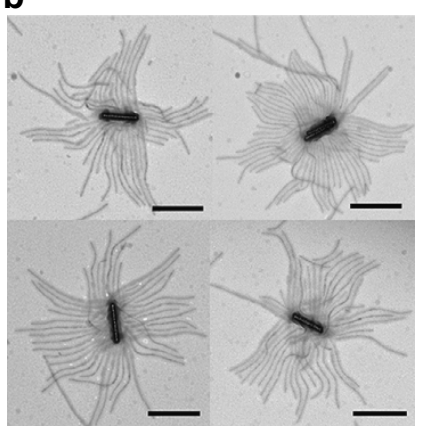

c

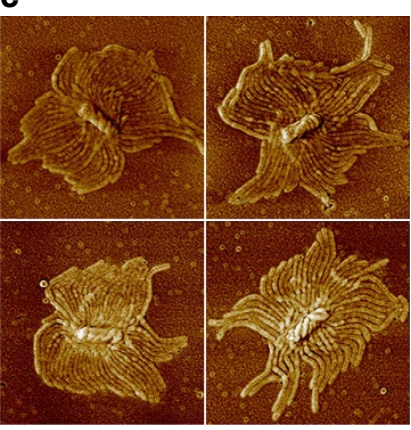

e

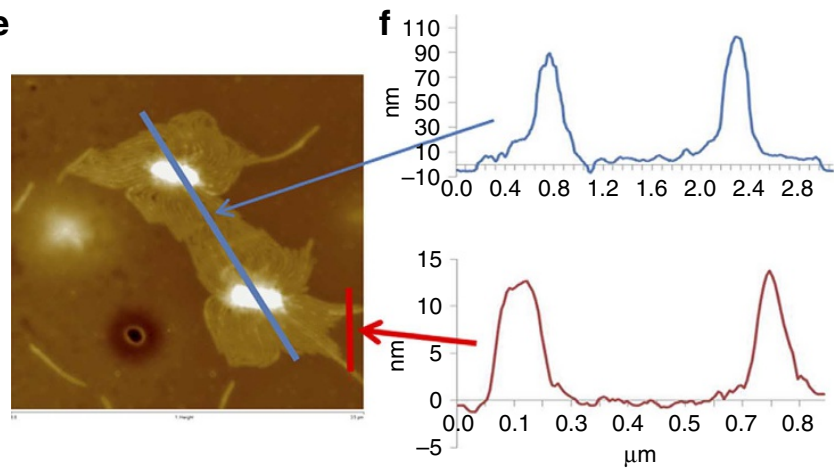

Figure 3 | Preparation of butterfly-like assemblies through seeded growth. (a) TEM image of $\mathrm{PFS}_{30}-b-\mathrm{P}_{2} \mathrm{VP} \mathrm{P}_{300}$ seed-coated $\mathrm{SiO}{ }_{2} @ \mathrm{Ni}-\mathrm{NRs} 3 \mathbf{3 a}$ after removal of the excess $\mathrm{PFS}_{30}-b-\mathrm{P}_{2} \mathrm{VP}_{300}$ crystallites. The inset shows a single seed-coated NR at higher magnification. Scale bar, $500 \mathrm{~nm}$ (inset is $100 \mathrm{~nm}$ ). (b) TEM image of butterfly-like hybrid assemblies. Scale bars, $500 \mathrm{~nm}$. $3 \mathbf{b}$ prepared by addition of $\mathrm{PFS}_{30}-b-\mathrm{P}_{2} \mathrm{VP}_{300}$ in $\mathrm{THF}\left(10 \mu \mathrm{l}, 10 \mathrm{mg} \mathrm{ml}{ }^{-1}\right)$ to 2-propanol (1 ml) containing seed-coated $\mathrm{SiO}_{2} @ N i-N R s\left(0.08 \mathrm{mg} \mathrm{ml}^{-1}\right.$ ) and aged for $24 \mathrm{~h}$. (c) AFM phase images of the butterfly-like hybrid assemblies 3b. Each image is $2 \times 2 \mu \mathrm{m}$. (d) Three-dimensional AFM height image of a single $\mathbf{3 b}$ assembly. Scale bar, $500 \mathrm{~nm}$. (e) AFM height image (size: $3.5 \times 3.5 \mu \mathrm{m}$ ) of two of butterfly-like hybrid assemblies. (f) A section analysis of the two structures in $\mathbf{e}$ along the blue and red lines, respectively. The height of the micelle-coated rods is $\sim 95 \mathrm{~nm}$, and the height of the micelles themselves is $15 \mathrm{~nm}$.

integrity over the course of these modifications. They also suggest that it is possible to introduce a variety of different inorganic NPs at specific locations along the micelles.

\section{Discussion}

In summary, we have demonstrated a new and versatile approach to fabricate colloidal mesoscale hybrid assemblies consisting of brushes of cylindrical BCP micelles attached to the surface of silica-coated NPs of arbitrary shape. The key step in the fabrication design was to attach seed crystallites of the BCP micelles to the NP surface followed by CDSA of added BCP. In this way, core-crystalline micelles grow from the NP surface. In the case where the newly added polymer carried positive charges in the corona, its locus in the brush could be further functionalized by selective adsorption of negatively charged $\mathrm{Au}$ NPs. This procedure also demonstrates that the hybrid mesostructures are sufficiently robust to be post-modified. Although the specific proof of concept example described here involved $\mathrm{PFS}_{30}-b-\mathrm{P}_{2} \mathrm{VP}_{300}$ as the micelle forming polymer, the fabrication protocol should in principle apply to any $\mathrm{BCP}$ that forms elongated core-crystalline micelles and to any substrate to which the corona chains of the seed crystallites can attach. For example, we have recently shown that CDSA can be extended to BCP micelles with a conjugated crystalline polythiophene core $^{22,37}$. An interesting system for future studies would be hybrids consisting of polythiophene BCP micelles and titanium oxide NPs to generate potential light harvesting photovoltaic structures. Thus we anticipate that a broad variety of novel, interesting and ultimately functional mesostructures can be created in this way.

\section{Methods}

Materials. Tetrahydrofuran (THF, ACS reagent, $\geq 99.0 \%$ ), isopropanol (2-PrOH, $\geq 99.5 \%$ ), hexane ( $\geq 99.8 \%$ ), tetraethyl orthosilicate (TEOS, $\geq 99.0 \%$ ), didodecyldimethylammonium bromide (DDAB, 98\%), mercaptoacetic acid ( $\geq 98 \%)$, Brij 58 , diethylamine ( $\geq 99.5 \%$ ), hydrazine hydrate (reagent grade, $50-60 \%$ ), nickel dichloride $\left(\mathrm{NiCl}_{2}, 98 \%\right)$, dodecylamine $(\geq 99 \%)$, gold(III) chloride $\left(\mathrm{AuCl}_{3}, 99 \%\right)$, TBAB (tetra- $n$-butylammonium bromide, $\geq 98 \%$ ), tetramethylammonium hydroxide $\left(\mathrm{Me}_{4} \mathrm{~N}^{+}[\mathrm{OH}]^{-}, 10 \%\right.$ in water) were purchased from Sigma-Aldrich and used as received. $\mathrm{PFS}_{30}-b-\mathrm{P} 2 \mathrm{VP}_{300}\left(M_{\mathrm{n}, \mathrm{GPC}}=30,400, \mathrm{PDI}=1.17\right)$ is the same sample reported in ref. 32 , and was synthesized by $\mathrm{He}$ et al. by sequential anionic polymerization.

Electron microscopy. Bright-field transmission electron microscopy (TEM) images were taken using a Hitachi H-7000 instrument. For each sample, micelle length distributions were determined by tracing more than 100 individual micelles or corona micelles grown from NPs or NRs using the software Image (NIH, US). Dark-field TEM images were taken using a FEI QUANTA model FEG 250 ESEM with a BF/DF STEM detector in the high vacuum mode with an accelerating voltage of $30 \mathrm{kV}$. Scanning electron microscopy (SEM) images were taken using a Hitachi S-5200 SEM instrument. Energy-dispersive X-ray spectroscopy (EDX) analysis for PFS- $b$-P2VP unimers or seed-coated silica NPs were taken using an EDX attachment (INCA, Oxford Instruments) on the Hitachi S-5200 SEM instrument. Composition-based line scans were carried out on relevant particles identified on the sample grid. The accelerating voltage for EDX measurements was $15 \mathrm{kV}$, and the current was $20 \mu \mathrm{A}$. Data were collected over a period of $5 \mathrm{~min}$. EDX was used to determine the incorporation of PFS- $b$-P2VP copolymers or seeds onto the surface of silica NPs.

Samples were prepared by placing one drop of solution on a Formvar-carbon coated grid, touching the edge of the droplet with a filter paper to remove excess liquid and allowing the grid to dry. The number average lengths $\left(L_{n}\right)$ and weight average lengths $\left(L_{\mathrm{w}}\right)$ of the micelles were calculated from the TEM images by 


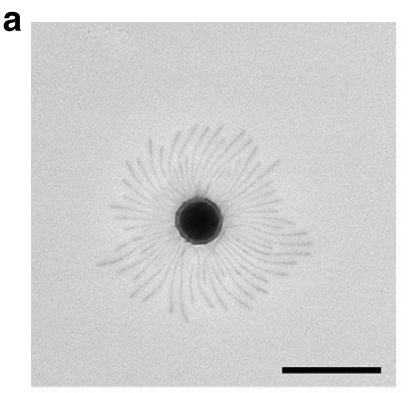

b

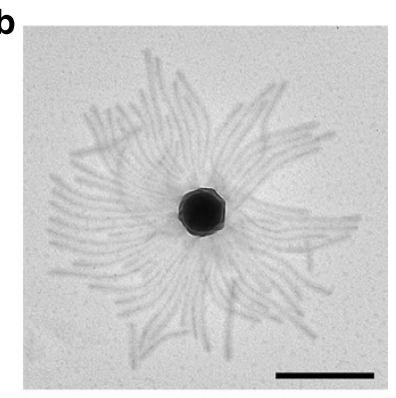

$+2.5 \mu$ l of unimer in THF $\left(10 \mathrm{mg} \mathrm{ml}^{-1}\right)$

C
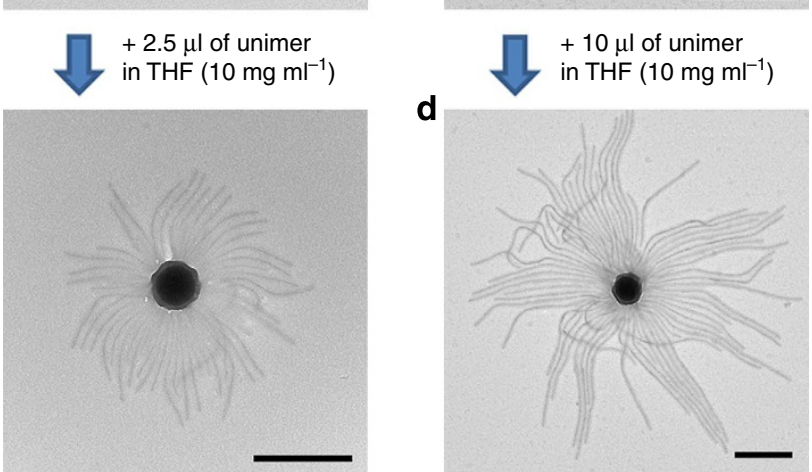

Figure 4 | Controlling micelle length in hybrid constructions. TEM images of the structures obtained by adding different amounts (a, $10 \mu \mathrm{l}$ or $\mathbf{b}, 20 \mu \mathrm{l})$ of $\mathrm{PFS}_{30}-b-\mathrm{P}_{2} \mathrm{VP}_{300}$ in THF $\left(10 \mathrm{mg} \mathrm{ml}^{-1}\right)$ to $2-\mathrm{PrOH}$ solutions $(1 \mathrm{ml})$ of seed-coated $\mathrm{SiO}_{2} \mathrm{NPs}(0.25 \mathrm{mg})$, then aging $24 \mathrm{~h}$ at room temperature. (c) Two-step micelle growth. Hybrid sunflower structures $\mathbf{4 c}$ with elongated petals obtained by adding an aliquot of $\mathrm{PFS}_{30}-b-\mathrm{P}_{2} \mathrm{VP}_{300}$ in $\mathrm{THF}(2.5 \mu \mathrm{l}$, $10 \mathrm{mg} \mathrm{ml}^{-1}$ ) to a $2-\mathrm{PrOH}$ solution $(0.5 \mathrm{ml})$ of the sunflower assemblies $\mathbf{4 a}$ shown in a. (d) Larger structures $\mathbf{4 d}$ obtained by adding $\mathrm{PFS}_{30}-b-\mathrm{P}_{2} \mathrm{VP}_{300}$ in THF $\left(10 \mu l, 10 \mathrm{mg} \mathrm{ml}^{-1}\right)$ to a 2-PrOH solution $(0.5 \mathrm{ml})$ of the assemblies $\mathbf{4 b}$ shown in $\mathbf{b}$. Both solutions were aged for $24 \mathrm{~h}$ after the second addition of $\mathrm{PFS}_{30}-b-\mathrm{P}_{2} \mathrm{VP}_{300}$. Scale bars, $500 \mathrm{~nm}$. tracing by hand more than 100 individual micelles or corona micelles using the software ImageJ (NIH, US). Values of $L_{\mathrm{n}}$ and $L_{\mathrm{w}}$ were calculated as

$$
\begin{gathered}
L_{\mathrm{n}}=\frac{\sum_{i=1}^{N} N_{i} L_{i}}{\sum_{i=1}^{N} N_{i}} \\
L_{\mathrm{w}}=\frac{\sum_{i=1}^{N} N_{i} L_{i}^{2}}{\sum_{i=1}^{N} N_{i} L_{i}}
\end{gathered}
$$

where $N_{i}$ is the number of micelles of length $L_{i}$, and $N$ is the total number of micelles examined for each sample. The distribution of micelle lengths $\left(\mathrm{PDI}_{\mathrm{TEM}}\right)$ is characterized by $L_{\mathrm{w}} / L_{\mathrm{n}}$. The number and weight average diameters of the silica NPs $\left(d_{\mathrm{n}}, d_{\mathrm{w}}\right)$, the number average lengths $\left(L_{\mathrm{n}, \mathrm{rod}}, L_{\mathrm{w}, \text { rod }}\right)$ and the average widths $\left(W_{\mathrm{n}, \text { rod }}\right.$, $\left.W_{\mathrm{w}, \mathrm{rod}}\right)$ of the silica-coated nickel-hydrazine complex, and the average thicknesses $\left(T_{\mathrm{n}}, T_{\mathrm{w}}\right)$ of the silica layer or polymer layer and their distributions were calculated in a similar way.

Atomic force microscopy. AFM measurements were carried out with an instrument (Digital Instruments, Dimension 5000, Nanoscope IIIa, US) using the same samples prepared for TEM. High resonance frequency silicon probes with spring constant $42 \mathrm{~N} \mathrm{~m}^{-1}$, resonance frequency $\sim 320 \mathrm{kHz}$, (NanoWorld, Switzerland) were used for tapping-mode imaging in air. The scan rate was $1 \mathrm{~Hz}$ and the collected images were 512 pixels $\times 512$ pixels. Height and phase images were analysed by software (Nanoscope V1.40).

Dynamic light scattering. The hydrodynamic diameters and polydispersity index (PDI) of silica NPs in THF or 2-PrOH, silica NPs mixed with PFS- $b$-P2VP unimers in THF and silica NPs mixed with PFS- $b$-P2VP seeds in 2-PrOH (Supplementary Table 1) were determined with a BI-90 particle sizer (Brookhaven Instruments Corporation, Holtsville, NY). For some selected samples, the autocorrelation and CONTIN plots of the sunflower hybrid assembly (Supplementary Fig. 10e,f) were obtained using an ALV/ DLS/SLS-5000 Compact Goniometry System equipped with a vertically polarized He-Ne laser $\left(\lambda_{0}=632.8 \mathrm{~nm}, 35 \mathrm{~mW}\right)$ as the light source and a Dual ALV-High Q.E. APD avalanche photodiode module connected to an ALV-5000/EPP multiple digital time correlator as the detection module. The experiments were performed at $90^{\circ}$. For the measurement, the sample was sealed in a screw-capped vial and immersed in a toluene vat which matched the index of refraction of the glass vial.

Partially quaternized $\mathbf{P F S}_{\mathbf{3 0}} \mathbf{- b}-\mathbf{P 2} \mathbf{V P}_{\mathbf{3}}^{\mathbf{O} 0}$. The partially quaternized $\mathrm{PFS}_{30}-b$ ${\mathrm{P} 2 \mathrm{VP}_{300}}_{30}$ copolymer was prepared following the protocol described in ref. 36.
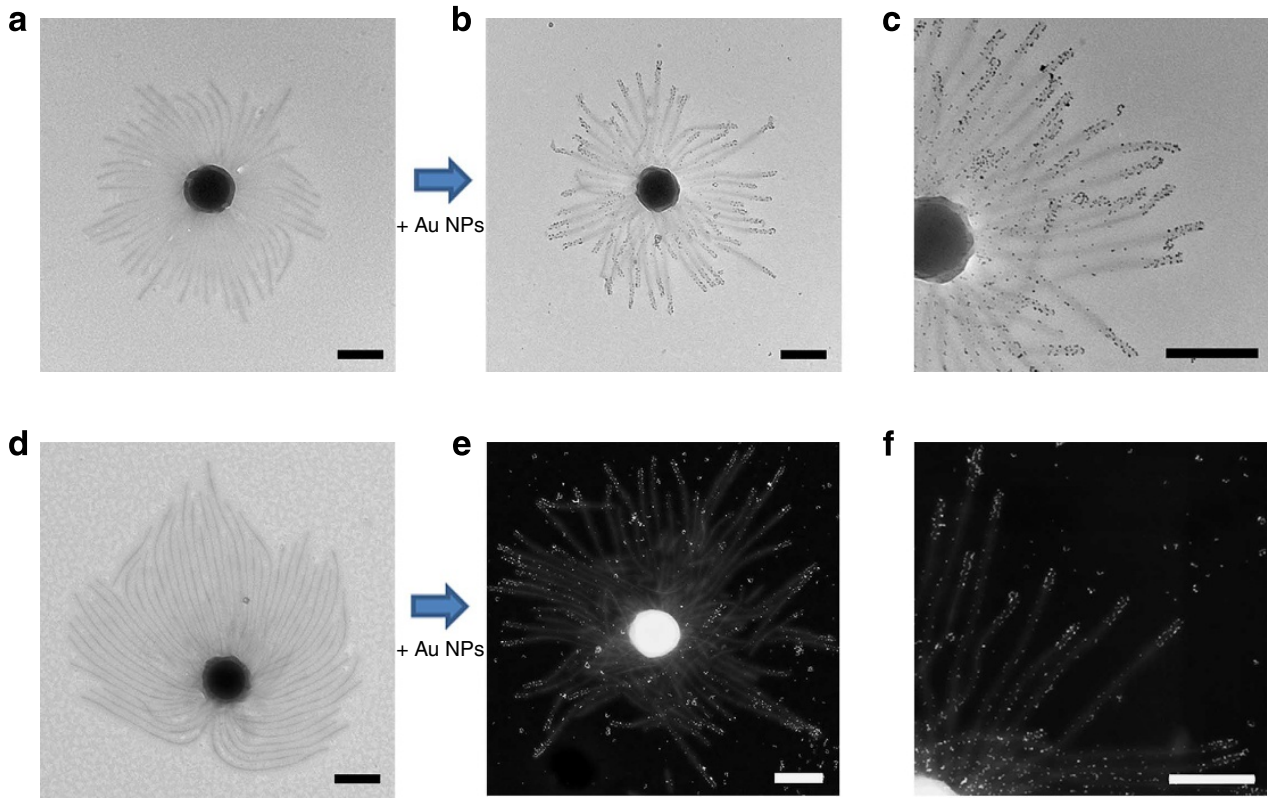

Figure 5 | Sunflower-like assemblies with partially functionalized petals. (a) TEM image of sample $\mathbf{5 a}$ obtained by the addition of the partially quaternized block copolymer $\mathrm{PFS}_{30}-b-\mathrm{P} 2 \mathrm{VP} \mathrm{O}_{300}$ to $\mathbf{4 a}$ in 2-PrOH. (d) TEM image of sample $\mathbf{5 d}$ obtained by addition of $\mathrm{PFS}_{30}-b-\mathrm{P} 2 \mathrm{VP} \mathrm{O}_{300}$ to $\mathbf{4} \mathbf{b}$ in $2-\mathrm{PrOH}$. Both solutions were aged for $24 \mathrm{~h}$ at room temperature. (b,e) Treatment of $\mathbf{5 a}$ and $\mathbf{5 d}$ in 1:1 2- $\mathrm{PrOH} / \mathrm{H}_{2} \mathrm{O}$ with negatively charged Au NPs, led to the structures $\mathbf{5 b} \mathbf{b}(\mathbf{b})$ and $\mathbf{5 e}$ (dark-field TEM image, e, respectively. (c) Higher magnification image from a different position of the same grid used to obtain the image in b. (f) Higher magnification image from a different position of the same grid used to obtain the image in e. Scale bars, $250 \mathrm{~nm}$. 
Cylindrical micelles were first prepared by dissolving $\mathrm{PFS}_{30}-b-\mathrm{P}_{2} \mathrm{VP}_{300}(5 \mathrm{mg})$ in THF $(100 \mu \mathrm{l})$, adding this solution to 2-PrOH $(5 \mathrm{ml})$, and setting it aside to age for $24 \mathrm{~h}$. This sample was briefly sonicated using a $70 \mathrm{~W}$ ultrasonic bath to shorten the length of the micelles. To this solution $(5.0 \mathrm{mg}$ per $5 \mathrm{ml}$, pyridyl group content: $\left.4.9 \times 10^{-2} \mathrm{mmol}\right)$ was added MeI $\left(3.0 \mu \mathrm{l}, 4.9 \times 10^{-2} \mathrm{mmol}\right)$ at room temperature with stirring. After $24 \mathrm{~h}$, the solvent was evaporated, and the product was purified by dissolution in THF followed by precipitation and washing with hexane. This cycle was repeated three times and the partially quaternized polymer was dried under vacuum at room temperature for 2 days. The degree of quaternization was evaluated by ${ }^{1} \mathrm{H}$ NMR in $\mathrm{d}_{6}$-dimethylsulphoxide, noting that after quaternization, the chemical shift of the $\alpha-\mathrm{H}$ in pyridine ring shifted from 8.26 to 8.67 p.p.m. A degree of quaternization of $\sim 3.2 \%$ was determined by comparing the integrated ${ }^{1} \mathrm{H}$ NMR signals of the shifted $\alpha-\mathrm{H}$ peak at 8.67 p.p.m. to that of the $\alpha-\mathrm{H}$ peak at 8.26 p.p.m. in the pyridine ring.

Gold nanoparticles coated with 2-mercaptoacetic acid. Au NPs were synthesized following the procedure described in ref. 36. Briefly, DDAB was dissolved in toluene to make a $100 \mathrm{mM}$ stock solution. Gold(III) chloride $\left(\mathrm{AuCl}_{3}, 7.5 \mathrm{mg}\right)$ was dissolved by sonication in the DDAB solution $(2.5 \mathrm{ml})$ leading to an orange-red colour. Dodecylamine $(18 \mathrm{mg})$ was dissolved in $0.5 \mathrm{ml}$ of the DDAB solution by sonication and added to the solution containing $\mathrm{AuCl}_{3}$. In another vial TBAB $(25 \mathrm{mg})$ was dissolved in $1 \mathrm{ml}$ of the DDAB solution and injected into the gold salt solution under vigorous stirring at room temperature. The colour of the solution turned dark brown immediately suggesting the formation of Au NPs. To perform ligand exchange with mercaptoacetic acid, $1 \mathrm{ml}$ of methanol was added to the $\mathrm{Au}$ NP solution $(0.5 \mathrm{ml})$. The NPs precipitated immediately, were collected by centrifugation, and then redispersed in $0.5 \mathrm{ml}$ of toluene. To this solution was added about $10 \mathrm{mg}$ of mercaptoacetic acid. The Au NPs precipitated immediately and were collected by centrifugation. After washing the precipitate with toluene $(1 \times 1 \mathrm{ml})$, methanol $(3 \times 1 \mathrm{ml})$ and water $(3 \times 1 \mathrm{ml})$, the Au NPs were redispersed in $0.5 \mathrm{ml}$ water containing sufficient $10 \%$ aqueous solution of $\mathrm{Me}_{4} \mathrm{~N}^{+}[\mathrm{OH}]$ to raise the $\mathrm{pH}$ to 10 . By TEM, the mean diameter of the Au NPs was $\sim 2 \mathrm{~nm}$.

Preparation of PFS- $\boldsymbol{b}$-P2VP seed crystallites. $\mathrm{PFS}_{30}-b$ - $\mathrm{P}_{2} \mathrm{VP}_{300}$ seed crystallites were prepared in two steps. First, long micelles were prepared by dissolving the polymer $(1 \mathrm{mg})$ in THF $(100 \mu \mathrm{l})$, adding this solution to 2 - $\mathrm{PrOH}(2 \mathrm{ml})$, and setting it aside to age for $24 \mathrm{~h}$. This mixture was then sonicated at room temperature for three 10 -min periods using a $70 \mathrm{~W}$ ultrasonic bath. The micelle seed fragments obtained $\left(L_{\mathrm{n}}=60 \mathrm{~nm}, \mathrm{PDI}_{\mathrm{TEM}}=1.09\right)$ were characterized by measuring over 200 seeds in several TEM images.

Preparation of silica nanoparticles $\left(\mathrm{SiO}_{\mathbf{2}} \mathbf{~ N P s}\right)$. Silica $\mathrm{NPs}\left(\mathrm{SiO}_{2} \mathrm{NPs}\right)$ were prepared by a modified Stöber method as described in ref. 38. Briefly, TEOS $(9 \mathrm{ml})$ was slowly added to a mixture of ethanol $(150 \mathrm{ml})$, deionized water $(15 \mathrm{ml})$, and aqueous ammonia $(27 \%, 3 \mathrm{ml})$ at room temperature. The mixture was stirred vigorously for $24 \mathrm{~h}$. The $\mathrm{SiO}_{2}$ NPs were purified by three sedimentationresuspension cycles in a 1:1 ethanol:deionized water mixture. Finally, a dried powder of NPs $\left(\mathrm{SiO}_{2} \mathrm{NPs}\right)$ was obtained by freeze-drying over $24 \mathrm{~h}$. The number average diameter $\left(d_{\mathrm{n}}\right)$ of the $\mathrm{SiO}_{2} \mathrm{NPs}$ was $246 \mathrm{~nm}, \mathrm{PDI}_{\mathrm{TEM}}=1.01$, evaluated by measuring over $100 \mathrm{SiO}_{2} \mathrm{NPs}$ in several TEM images.

Preparation of $\mathbf{S i O}_{\mathbf{2}} @ \mathbf{N i}$-NRs. The silica-coated nickel-hydrazine complex NRs $\left(\mathrm{SiO}_{2} @ \mathrm{Ni}-\mathrm{NRs}\right)$ were synthesized following the procedure described in ref. 35. Brij $58(8.5 \mathrm{~g})$ was dissolved in cyclohexane $(15 \mathrm{ml})$ at $50^{\circ} \mathrm{C}$. Then, a $\mathrm{NiCl}_{2}$ solution in water $\left(1.7 \mathrm{ml}, 0.1 \mathrm{~g} \mathrm{ml}^{-1}\right)$ was added and stirred until a homogeneous solution was obtained. Hydrazine hydrate $(0.45 \mathrm{ml})$ was added dropwise. The mixture was stirred for $3 \mathrm{~h}$. Then, diethylamine $(1 \mathrm{ml})$ and subsequently TEOS $(3 \mathrm{ml})$ were added to the system. The silica coating process was allowed to proceed for $2 \mathrm{~h}$, followed by centrifugation and washing with ethanol ( $40 \mathrm{ml}$, three times) and 2-PrOH (40 ml, three times). Finally, the $\mathrm{SiO}_{2} @ \mathrm{Ni}-\mathrm{NRs}$ were dispersed in 2-PrOH $(25 \mathrm{ml})$ as a stock solution for further experiments. The solids concentration was $32.2 \mathrm{mg} \mathrm{ml}^{-1}$. The number average length $\left(L_{\mathrm{n}, \mathrm{rod}}\right)$ of the $\mathrm{SiO}_{2} @ \mathrm{Ni}-\mathrm{NRs}$ was $375 \mathrm{~nm}\left(\mathrm{PDI}_{\mathrm{TEM}}=1.01\right)$, with a number average width $\left(W_{\mathrm{n}, \mathrm{rod}}\right)$ of $93 \mathrm{~nm}$ $(\mathrm{PDI}=1.06)$; the number average thickness $\left(T_{\mathrm{n}}\right)$ of the silica layer was $30 \mathrm{~nm}$ $\left(\mathrm{PDI}_{\mathrm{TEM}}=1.03\right)$. These values were evaluated by measuring over $100 \mathrm{NRs}\left(L_{\mathrm{n}, \mathrm{rod}}\right)$ or 100 positions along the rods $\left(W_{\mathrm{n}, \text { rod }}, T_{\mathrm{n}}\right)$ in several TEM images.

Preparation of PFS-b-P2VP seed-coated NPs $\mathbf{1 b}$ and 3a. Two kinds of $\mathrm{PFS}_{30}-\boldsymbol{b}$ $\mathrm{P}_{2} \mathrm{VP}_{300}$ seed-coated NPs $\left(\mathrm{SiO}_{2} \mathrm{NPs}\right.$ or $\left.\mathrm{SiO}_{2} @ \mathrm{Ni}-\mathrm{NRs}\right)$ were prepared by the same procedure. For structures $\mathbf{1 b}$, a sample of $\mathrm{SiO}_{2} \mathrm{NPs}(1 \mathrm{mg})$ was dispersed in 2-PrOH $(1 \mathrm{ml})$, followed by the addition of a $2-\mathrm{PrOH}$ solution $(1 \mathrm{ml})$ containing $\mathrm{PFS}_{30}-b-\mathrm{P} 2 \mathrm{VP}_{300}$ seeds $\left(0.5 \mathrm{mg}, L_{\mathrm{n}}=60 \mathrm{~nm}\right)$. The mixture was stirred $24 \mathrm{~h}$, and a drop of the solution was taken for TEM image analysis (Fig. 1a and Supplementary Fig. 3). Excess seeds were removed by three sedimentation-resuspension cycles. As part of each resuspension step, the samples were sonicated briefly $(\sim 2 \mathrm{~s})$ in a $70 \mathrm{~W}$ ultrasonic bath. Finally, the $\mathrm{PFS}_{30}-b-\mathrm{P}_{2} \mathrm{VP}_{300}$ seed-coated $\mathrm{SiO}_{2} \mathrm{NPs}$ were redispersed in 2-PrOH $(2 \mathrm{ml}$ ) for TEM image analysis (Fig. $1 \mathrm{~b}$ and Supplementary Fig. 4). An EDX line scan showing strong signals for $\mathrm{Fe}$ and $\mathrm{N}$ is presented in
Supplementary Fig. 5. An EDX line scan of the precursor $\mathrm{SiO}_{2}$ NPs shows no signal for Fe (Supplementary Fig. 13) or N (not shown).

Structures 3a were prepared by the same method. A 2-PrOH solution $(1 \mathrm{ml})$ containing $\mathrm{PFS}_{30}-b-\mathrm{P} 2 \mathrm{VP}_{300}$ seeds $\left(0.15 \mathrm{mg}, L_{\mathrm{n}}=60 \mathrm{~nm}\right)$ was mixed with a 2-PrOH solution $(1 \mathrm{ml})$ containing dispersed $\mathrm{SiO}_{2} @ \mathrm{Ni}-\mathrm{NRs}(0.16 \mathrm{mg})$. The mixture was stirred $24 \mathrm{~h}$, and a drop of the solution was taken for TEM image analysis. Excess seeds were removed by three sedimentation-resuspension cycles, and the samples were sonicated briefly during each resuspension step. Finally, the $\mathrm{PFS}_{30^{-}}-b$ $\mathrm{P}_{2} \mathrm{VP}_{300}$ seed-coated $\mathrm{SiO}_{2} @ \mathrm{Ni}$-NRs were redispersed in 2-PrOH $(2 \mathrm{ml})$.

Coating $\mathrm{SiO}_{\mathbf{2}}$ NPs with PFS-b-P2VP unimers in THF. A sample of $\mathrm{SiO}_{2} \mathrm{NPs}$ $(1 \mathrm{mg})$ dispersed in THF was treated with a solution of $\mathrm{PFS}_{30}-b$ - $\mathrm{P}_{2} \mathrm{VP}_{300}$ (THF $1 \mathrm{mg}, 2 \mathrm{ml}$ ), stirred $24 \mathrm{~h}$, purified by sedimentation-redispersion, and examined by TEM and EDX spectroscopy. EDX line scan analysis of these $\mathrm{SiO}_{2} \mathrm{NPs}$ (Supplementary Fig. 14) showed small $\mathrm{Fe}$ and $\mathrm{N}$ peaks, indicating the presence of a very thin film of $\mathrm{BCP}$ on the surface of the $\mathrm{SiO}_{2} \mathrm{NPs}$. These particles were then transferred to $2-\mathrm{PrOH}$ and treated with a solution of $\mathrm{PFS}_{30}-b-\mathrm{P}_{2} \mathrm{VP}_{300}$ in THF $\left(80 \mu \mathrm{l}, 10 \mathrm{mg} \mathrm{ml}^{-1}\right)$ in an attempt to induce the growth of $\mathrm{PFS}_{30}-b-\mathrm{P}_{2} \mathrm{VP}_{300}$ micelles from the surface of the NPs. TEM images taken after $24 \mathrm{~h}$ (Supplementary Fig. 15) showed a superposition of long fibre-like BCP micelles and isolated silica NPs. Both species remained colloidally stable upon aging for several days.

Preparation of samples $\mathbf{1} \mathbf{c}$ and $\mathbf{3} \mathbf{b}$ by seeded growth. For micelles@SiO $\mathrm{S}_{2} \mathrm{NPs}$ (1c), an aliquot of $\mathrm{PFS}_{30^{-}} b-\mathrm{P}_{2} \mathrm{VP}_{300}$ in THF $\left(15 \mu \mathrm{l}, 10 \mathrm{mg} \mathrm{ml}^{-1}\right)$ was added to a 2-PrOH solution $(1 \mathrm{ml})$ containing $\mathrm{PFS}_{30}-b-\mathrm{P}_{2} \mathrm{VP}_{300}$ seed-coated $\mathrm{SiO}_{2} \mathrm{NPs}(0.5 \mathrm{mg}$ of $\mathrm{SiO}_{2} \mathrm{NPs}$ purified to remove excess of $\mathrm{PFS}_{30}-b$ - $\mathrm{P}_{2} \mathrm{VP}_{300}$ seeds). After brief swirling, the solution was allowed to age for $24 \mathrm{~h}$. Humidity affected the appearance of the self-assembled structures: when the sample was deposited on the TEM grid on a humid day, the micelle petals of the sunflower assemblies tended to stick together (see Supplementary Fig. 16). To eliminate the effect of humidity on sample preparation for TEM imaging, we prepared all TEM samples in a glove bag under a dry nitrogen atmosphere.

To grow micelles from the surface of $\mathrm{SiO}_{2} @ \mathrm{Ni}-\mathrm{NRs}$, an aliquot of $\mathrm{PFS}_{30}-b$ $\mathrm{P}^{2} \mathrm{VP}_{300}$ in THF $\left(10 \mu \mathrm{l}, 10 \mathrm{mg} \mathrm{ml}^{-1}\right)$ was added to a $2-\mathrm{PrOH}$ solution $(1 \mathrm{ml})$ containing seed-coated $\mathrm{SiO}_{2} @ \mathrm{Ni}-\mathrm{NRs}\left(0.08 \mathrm{mg}\right.$ of $\mathrm{SiO}_{2} @ \mathrm{Ni}$-NRs purified to remove excess seeds). After brief swirling, the solution was allowed to age for $24 \mathrm{~h}$.

Preparation of sample 1d by self-seeding. A 2-PrOH solution $(2 \mathrm{ml})$ containing a mixture of $\mathrm{SiO}_{2} \mathrm{NPs}(1 \mathrm{mg})$ and $\mathrm{PFS}_{30}-b$ - $\mathrm{P}_{2} \mathrm{VP}_{300}$ seeds $(0.8 \mathrm{mg})$ was subjected to two successive heating/cooling cycles. The solution was first heated at $90^{\circ} \mathrm{C}$ for $30 \mathrm{~min}$, cooled to room temperature, and then aged for $24 \mathrm{~h}$. A drop of the sample was taken out for TEM image analysis. The remaining solution was re-heated at $90^{\circ} \mathrm{C}$ for $90 \mathrm{~min}$, cooled to room temperature, and aged for another $24 \mathrm{~h}$ before aliquots were taken for analysis by TEM.

Controlling petal length of samples $\mathbf{4 a}$ and $\mathbf{4 b}$. An aliquot of a 2-PrOH stock solution $(1 \mathrm{ml})$ containing $\mathrm{PFS}_{30}-b$ - $\mathrm{P}_{2} \mathrm{VP}_{300}$ seed-coated $\mathrm{SiO}_{2} \mathrm{NPs}(0.5 \mathrm{mg})$ was diluted with 2-PrOH (1 ml), and divided into two portions. To one portion, an aliquot of $\mathrm{PFS}_{30}-b-\mathrm{P}_{2} \mathrm{VP}_{300}$ in THF $\left(10 \mu \mathrm{l}, 10 \mathrm{mg} \mathrm{ml}^{-1}\right)$ was added. The mixture was swirled briefly and then aged for $24 \mathrm{~h}$. A TEM image of the structures obtained $\left(L_{\mathrm{n}}=366 \mathrm{~nm}, \mathrm{PDI}_{\mathrm{TEM}}=1.04\right)$ are shown in Fig. $4 \mathrm{a}$ and Supplementary Fig. 9. We refer to this sample as sunflower $\mathbf{4 a}$.

To the second portion of seed solution a larger aliquot of $\mathrm{PFS}_{30}-b-\mathrm{P}_{2} \mathrm{VP}_{300}$ in THF $\left(20 \mu \mathrm{l}, 10 \mathrm{mg} \mathrm{ml}^{-1}\right)$ was added. The mixture was swirled briefly and then aged for $24 \mathrm{~h}$. A TEM image of the structures obtained $\left(L_{\mathrm{n}}=704 \mathrm{~nm}\right.$, $\mathrm{PDI}_{\mathrm{TEM}}=1.01$ ) are shown in Fig. $4 \mathrm{~b}$ and Supplementary Fig. 10. We refer to this sample as sunflower $\mathbf{4 b}$.

Petal elongation of samples $\mathbf{4 c}$ and $\mathbf{4 d}$. The sunflower hybrids $\mathbf{4 a}$ and $\mathbf{4 b}$ were used as starting materials for a second stage of seeded growth. After aging these samples for 2 days, they were treated with additional amounts $(2.5 \mu \mathrm{l}$ for $\mathbf{4 a}, 10 \mu \mathrm{l}$ for $\mathbf{4 b})$ of $\mathrm{PFS}_{30}-b-\mathrm{P}_{2} \mathrm{VP}_{300}$ in THF $\left(10 \mathrm{mg} \mathrm{ml}^{-1}\right)$. The mixtures were swirled for a few seconds and aged for $24 \mathrm{~h}$ before aliquots were taken for analysis by TEM. Representative images are presented in Fig. 4c,d and Supplementary Figs. 11 and 12 .

For petal elongation with $\mathrm{PFS}_{30}-b-\mathrm{P}_{2} \mathrm{VP}_{300}(\mathbf{5 a}$ and $\mathbf{5 d})$ and selective functionalization of the quaternized segments with Au NPs (5b,c and $\mathbf{5 e}, \mathbf{f})$, samples of sunflower hybrids $\mathbf{4 a}$ and $\mathbf{4 b}$ were each treated with a solution of $\mathrm{PFS}_{30}-b$-P2VPO ${ }_{300}$ in THF $\left(2.5 \mu \mathrm{l}, 10 \mathrm{mg} \mathrm{ml}^{-1}\right)$. The mixtures were swirled briefly and then aged for $24 \mathrm{~h}$. TEM images of the sunflower structures obtained in this way are shown in Fig. 5a (from sample 4a) and Fig. 5d (from sample 4b). To attach Au NPs to the quaternized segments, a sample of this solution $(50 \mu \mathrm{l})$ was diluted with an equal volume of water. Separately, a sample of negatively charged $\mathrm{Au}$ NPs was dispersed in water and treated with $\mathrm{Me}_{4} \mathrm{~N}^{+} \mathrm{OH}^{-}(10 \%$ in water) to bring the $\mathrm{pH}$ to 10 and the $\mathrm{Au} \mathrm{NP}$ concentration to $\sim 4 \mathrm{mM}$ ). Then $4 \mu \mathrm{l}$ of this solution was added to the $100 \mu \mathrm{l}$ sunflower block comicelle solution, swirled briefly and allowed to age for $3 \mathrm{~h}$ before grids were prepared for bright-field and dark-field TEM analysis. 


\section{References}

1. Glotzer, S. C. \& Solomon, M. J. Anisotropy of building blocks and their assembly into complex structures. Nat. Mater. 6, 557-562 (2007).

2. Yan, J., Bloom, M., Bae, S. C., Luijten, E. \& Granick, S. Linking synchronization to self-assembly using magnetic Janus colloids. Nature 491, 578-581 (2012).

3. Cui, H., Chen, Z., Zhong, S., Wooley, K. L. \& Pochan, D. J. Block copolymer assembly via kinetic control. Science 317, 647-650 (2007).

4. Xia, Y., Olsen, B. D., Kornfield, J. A. \& Grubbs, R. H. Efficient synthesis of narrowly dispersed brush copolymers and study of their assemblies: the importance of side chain arrangement. J. Am. Chem. Soc. 131, 18525-18532 (2009).

5. Ge, J., Lei, J. \& Zare, R. N. Protein-inorganic hybrid nanoflowers. Nat. Nanotechnol. 7, 428-432 (2012).

6. Cui, H. et al. Spontaneous and X-ray-triggered crystallization at long range in self-assembling filament networks. Science 327, 555-559 (2010).

7. Shrestha, R. et al. Hierarchically assembled theranostic nanostructures for siRNA delivery and imaging applications. J. Am. Chem. Soc. 134, 17362-17365 (2012).

8. Cheng, F., Bonder, E. M., Salem, S. \& Jäkle, F. Pyridine-functionalized luminescent organoboron quinolate block copolymers as versatile building blocks for assembled nanostructures. Macromolecules 46, 2905-2915 (2013).

9. Zhu, J., Zhang, S., Zhang, F., Wooley, K. L. \& Pochan, D. J. Hierarchical assembly of complex block copolymer nanoparticles into multicompartment superstructures through tunable interparticle associations. Adv. Funct. Mater. 23, 1767-1773 (2013).

10. Li, X., Liu, G. \& Han, D. Wrapping amino-bearing block copolymer cylinders around carboxyl-bearing nanofibers: a case of hierarchical assembly. Soft Matter 7, 8216-8223 (2011).

11. Gröschel, A. H. et al. Precise hierarchical self-assembly of multicompartment micelles. Nat. Commun. 3, 710 (2012).

12. Rupar, P. A., Chabanne, L., Winnik, M. A. \& Manners, I. Non-centrosymmetric cylindrical micelles by unidirectional growth. Science 337, 559-562 (2012).

13. Nie, Z., Petukhova, A. \& Kumacheva, E. Properties and emerging applications of self-assembled structures made from inorganic nanoparticles. Nat. Nanotechnol. 5, 15-25 (2010).

14. Tan, S. J., Campolongo, M. J., Luo, D. \& Cheng, W. Building plasmonic nanostructures with DNA. Nat. Nanotechnol. 6, 268-276 (2011).

15. Gao, B., Arya, G. \& Tao, A. R. Self-orienting nanocubes for the assembly of plasmonic nanojunctions. Nat. Nanotechnol. 7, 433-437 (2012).

16. Liu, K., Zhao, N. \& Kumacheva, E. Self-assembly of inorganic nanorods. Chem. Soc. Rev. 40, 656-671 (2011).

17. Liu, K. et al. Step-growth polymerization of inorganic nanoparticles. Science 329, 197-200 (2010).

18. Warner, M. G. \& Hutchison, J. E. Linear assemblies of nanoparticles electrostatically organized on DNA scaffolds. Nat. Mater. 2, 272-277 (2003).

19. Schreiber, R. et al. Hierarchical assembly of metal nanoparticles, quantum dots and organic dyes using DNA origami scaffolds. Nat. Nanotechnol. 9, 74-78 (2014).

20. Chou, L. Y. T., Zagorovsky, K. \& Chan, W. C. W. DNA assembly of nanoparticle superstructures for controlled biological delivery and elimination. Nat. Nanotechnol. 9, 148-155 (2014).

21. He, W.-N. \& Xu, J.-T. Crystallization assisted self-assembly of semicrystalline block copolymers. Prog. Polym. Sci. 37, 1350-1400 (2012).

22. Gwyther, J. et al. Dimensional control of block copolymer nanofibers with a $\pi$ conjugated core: crystallization-driven solution self-assembly of amphiphilic poly(3-hexylthiophene)-b-poly(2-vinylpyridine). Chem. Eur. J. 19, 9186-9197 (2013).

23. Petzetakis, N., Dove, A. P. \& O’Reilly, R. K. Cylindrical micelles from the living crystallization-driven self-assembly of poly(lactide)-containing block copolymers. Chem. Sci. 2, 955-960 (2011).

24. He, W.-N., Xu, J.-T., Du, B.-Y., Fan, Z.-Q. \& Wang, X. Inorganic-salt-induced morphological transformation of semicrystalline micelles of PCL-b-PEO block copolymer in aqueous solution. Macromol. Chem. Phys. 211, 1909-1916 (2010).
25. Schmelz, J., Schedl, A. E., Steinlein, C., Manners, I. \& Schmalz, H. Length control and block-type architectures in worm-like micelles with polyethylene cores. J. Am. Chem. Soc. 134, 14217-14225 (2012).

26. Wang, X. et al. Cylindrical block copolymer micelles and co-micelles of controlled length and architecture. Science 317, 644-647 (2007).

27. Wang, H., Winnik, M. A. \& Manners, I. Synthesis and self-assembly of poly(ferrocenyldimethylsilane-b-2-vinylpyridine) diblock copolymers. Macromolecules 40, 3784-3789 (2007).

28. Gädt, T., Ieong, N. S., Cambridge, G., Winnik, M. A. \& Manners, I. Complex and hierarchical micelle architectures from diblock copolymers using living, crystallization-driven polymerizations. Nat. Mater. 8, 144-150 (2009).

29. Gilroy, J. B. et al. Monodisperse cylindrical micelles by crystallization-driven living self-assembly. Nat. Chem. 2, 566-570 (2010).

30. Qian, J. et al. Self-seeding in one dimension: an approach to control the length of fiberlike polyisoprene-polyferrocenylsilane block copolymer micelles. Angew. Chem. Int. Ed. 50, 1622-1625 (2011).

31. Qi, F. et al. Influence of solvent polarity on the self-assembly of the crystallinecoil diblock copolymer polyferrocenylsilane-b-polyisoprene. Macromolecules 44, 6136-6144 (2011).

32. He, F. et al. Synthesis and self-assembly of fluorescent micelles from poly(ferrocenyldimethylsilane-b-2-vinylpyridine-b-2,5-di( $2^{\prime}$-ethylhexyloxy)1,4-phenylvinylene) triblock copolymer. Macromolecules 42, 7953-7960 (2009)

33. Qiu, H., Cambridge, G., Winnik, M. A. \& Manners, I. Multi-armed micelles and block co-micelles via crystallization-driven self-assembly with homopolymer nanocrystals as initiators. J. Am. Chem. Soc. 135, 12180-12183 (2013).

34. Xu, J., Ma, Y., Hu, W., Rehahn, M. \& Reiter, G. Cloning polymer single crystals through self-seeding. Nat. Mater. 8, 348-353 (2009).

35. Gao, C., Lu, Z. \& Yin, Y. Gram-scale synthesis of silica nanotubes with controlled aspect ratios by templating of nickel-hydrazine complex nanorods. Langmuir 27, 12201-12208 (2011)

36. Wang, H. et al. Cylindrical block co-micelles with spatially selective functionalization by nanoparticles. J. Am. Chem. Soc. 129, 12924-12925 (2007).

37. Qian, J. et al. Uniform, high aspect ratio fiber-like micelles and block comicelles with a crystalline $\pi$-conjugated polythiophene core by self-seeding. J. Am. Chem. Soc. 136, 4121-4124 (2014).

38. Stöber, W., Fink, A. \& Bohn, E. Controlled growth of monodisperse silica spheres in the micron size range. J. Colloid Interface Sci. 26, 62-69 (1968).

\section{Acknowledgements}

We thank NSERC Canada and the European Union for financial support. I.M. thanks the European Union for an ERC Advanced Investigator Grant.

\section{Author contributions}

L.J. conceived the project, performed the experiments and characterized the samples. G.Z. synthesized the inorganic NPs. AFM characterization was performed by W.S., supervised by G.C.W. Dark-field TEM imaging was carried out by N.C. and I.G. DLS experiments were performed by G.G., who also designed some experiments. L.J., G.G. and M.A.W. prepared the manuscript with input from I.M. The whole project was supervised by M.A.W. with input from I.M.

\section{Additional information}

Supplementary Information accompanies this paper at http://www.nature.com/ naturecommunications

Competing financial interests: The authors declare no competing financial interests.

Reprints and permission information is available online at http://npg.nature.com/ reprintsandpermissions/

How to cite this article: Jia, L. et al. A design strategy for the hierarchical fabrication of colloidal hybrid mesostructures. Nat. Commun. 5:3882 doi: 10.1038/ncomms4882 (2014). 